\title{
Studying the effects of coarse pore expanded clay concrete on a permanent formwork made of cement bonded particle boards
}

\author{
Aleksandr Sigalov ${ }^{1, *}$, Sergey Sinenko, Tatiana Poznahirko \\ ${ }^{1}$ Moscow State University Of Civil Engineering 129337, 26, Yaroslavskoe shosse, Moscow, Russian \\ Federation
}

\begin{abstract}
This paper suggests using a formwork system based on cement bonded particle boards (CBPB) filled with coarse pore expanded clay concrete in order to improve the technical efficiency of the building envelope. Such a structure is made of lightweight or honeycomb concrete units, has a thickness equal to that of heavyweight concrete blocks and provides increased resistance to heat, better fire resistance and longer durability. The relatively modest price of the suggested option is seen as a notable advantage. The effects of coarse pore expanded clay concrete have been shown as being similar to the effects of heavyweight concrete, with the nature of the effects demonstrated on a hydrostatic pressure curve. The author has substantiated the geometric parameters for the suggested heatefficient envelope design: a $800 \times 800 \times 370 \mathrm{~mm}$ block of CBPB filled with coarse-pore expanded clay concrete $\gamma=500 \mathrm{~kg} / \mathrm{m} 3$.
\end{abstract}

\section{Introduction}

This problem is urgent, because it is always necessary to reduce construction costs. The DSP has proved itself well on the part of the economy, but few have considered the issue of reliability. In connection with this, a number of experiments were in order to improve the technical efficiency of a building envelope, the author suggests using a formwork system based on cement bonded particle boards (CBPB) filled with coarse pore expanded clay concrete. Such a structure is made of lightweight or honeycomb concrete units, has a thickness equal to that of heavyweight concrete blocks and provides increased resistance to heat, better fire resistance and longer durability. The relatively modest price of the suggested option is seen as a notable advantage.

The issues in question have been studied by Ye.M. Pugach (Ph.D. in Technical Science), S.A. Sinenko (Doctor of Technical Science), I.Ye. Sigalov (Doctor of Technical Science), A.A. Afanasiev Doctor of Technical Science and many others. Some of the scholars suggested using either a temporary formwork or the types of formwork that

had poorer properties versus CBPB; others spoke in favor of CBPB filled with heavyweight concrete types. The combined use of CBPB and coarse pore expanded clay

\footnotetext{
* Corresponding author: sigalov2012@inbox.ru
} 
concrete is a relatively new approach in construction science and, therefore, it needs further review. Hence the study presented in this paper.

Construction scientists have determined the elasticity modulus of lightweight concretes to be dependent on the elastic characteristics of an aggregate and a mortar part and their relative amount in the concrete mass. Lightweight concrete has a relatively low modulus of elasticity due to increased deformation of porous aggregates. This is one of the most significant features of lightweight concrete, which, depending on the area of application and workability in structures, can play both a negative and a positive role.The elasticity modulus of a lightweight concrete aggregate is much lower than that of cement stone, but given the high degree of cement stone's intergrowth with the aggregate, the mortar part reduces stresses that occur in porous aggregate elements and causes a homogeneous distribution of such stresses. A large number of formulas are used to calculate the strength of lightweight concrete; however, these do not always take into account the effects of the aggregate contacts in coarse-pore structures and the adhesion of grains to the mortar, which results in these formulas being inaccurate.

Simulating the structure formation process for coarse-pore expanded clay concrete allows us to substantiate with more precision which processes occur in the material while it is mixed and cast in terms of the strength properties of the model.

The effects made by the deformative properties of the mixture allows the following conclusions to be drawn:

1. The deformability of a porous aggregate creates more favorable conditions for shrinkage in cement stone without forming cracks in it.

2. The full shrinkage value for densely structured lightweight concretes exceeds that for heavy concretes by $15-20 \%$ and can reach $1.5 \mathrm{~mm} / \mathrm{m}$.

3. The post-mold shrinkage value for most concretes using artificial porous aggregates ranges between 0.3 and $0.8 \mathrm{~mm} / \mathrm{m}$. The larger the volume and porosity of cement stone, the higher the post-mold shrinkage value.

4. After being cast, a lightweight concrete mixture differs from a regular heavyweight concrete mixture not only by a lower weight but by a significant air content some of which is compressed in the pores of lightweight concrete and causes the cast mixture to swell.

\section{Results}

Let us calculate the geometric parameters for a formwork made of CBPB.

For the purpose of this paper, an experimental unit shown in Figure 1 was used to carry out an experimental study of the lateral pressure of coarse pore expanded clay concrete on the walls of a formwork. This is a unit for experimental determination of deflections.

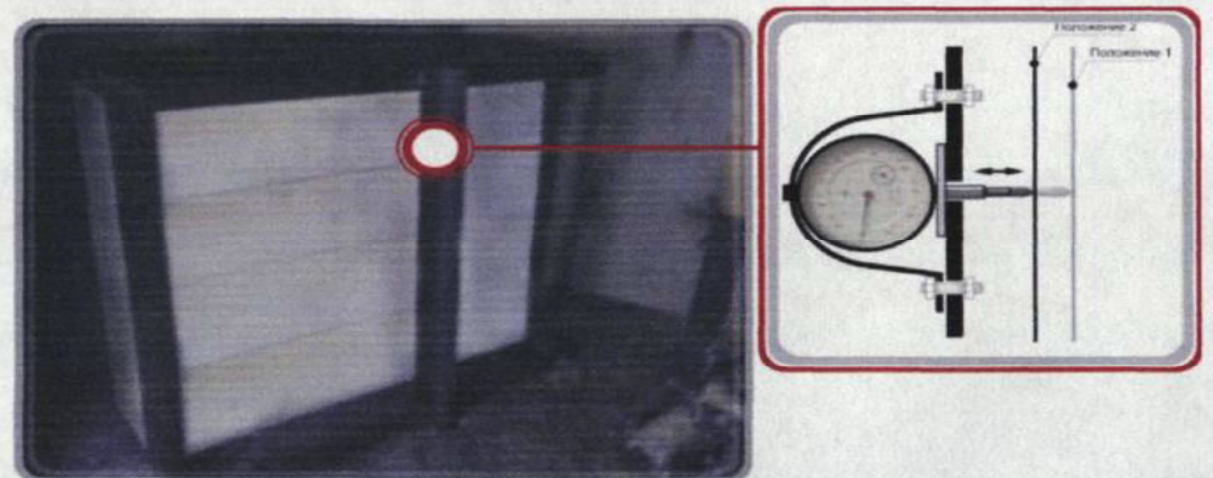

Fig.1 Example of mesurement 
Based on the computational model (Figure 2), we will calculate steel strips to determine the deflections in the side beam:
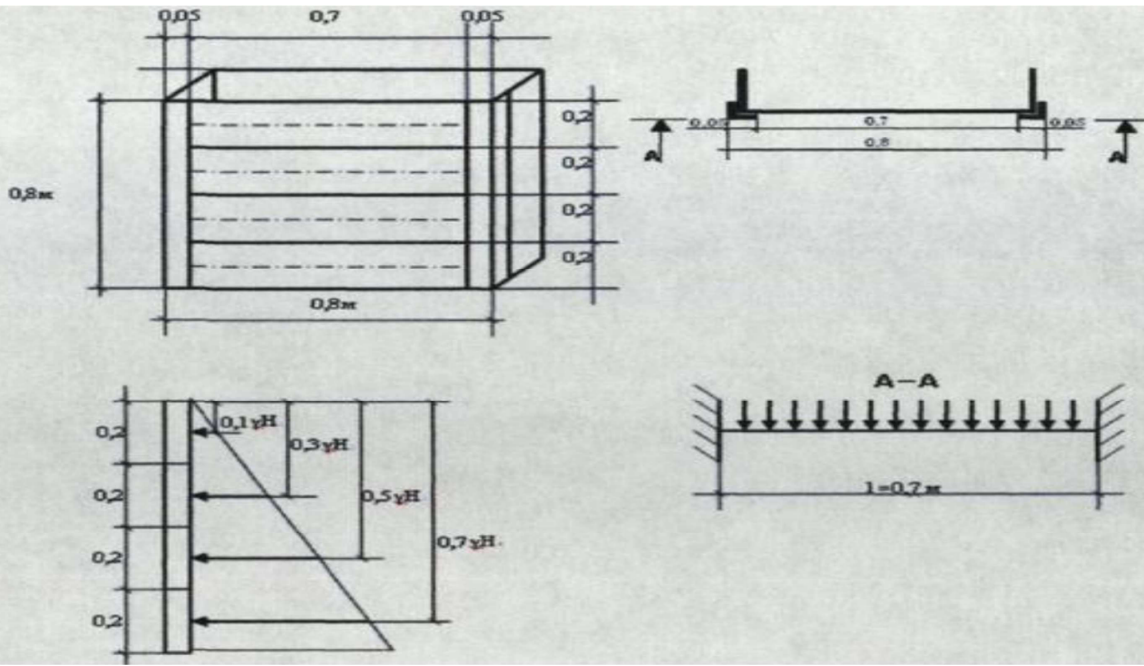

Fig. 2. The computational model for determining the lateral pressure

According to the Formula I, the load on the strip will be:

$P_{i}=\gamma H_{i} \bullet F$

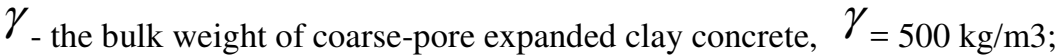

$\mathrm{Hi}$ - the arm of the force acting on the strip, $\mathrm{H}$;

F - strip area, $\mathrm{m} 2$;

$$
\begin{aligned}
& F=0.7 m \cdot 0.2=0,14 m^{2} \\
& P_{1}=500 \cdot 0.1 \cdot 0.14=7 \mathrm{~kg}=70 \mathrm{~N} \\
& P_{2}=500 \cdot 0.3 \cdot 0.14=21 \mathrm{~kg}=210 \mathrm{~N} \\
& P_{3}=500 \cdot 0.5 \cdot 0.14=35 \mathrm{~kg}=350 \mathrm{~N} \\
& P_{4}=500 \cdot 0.7 \cdot 0.14=49 \mathrm{~kg}=490 \mathrm{~N}
\end{aligned}
$$

Using Formula II, we will determine the deflection in the strip along the central axis $\int_{i}=\frac{P_{i} \cdot l_{i}}{E \cdot J} \cdot \frac{1}{384}$

$\mathrm{Pi}$ - concentrated load, $\mathrm{N}$;

$l_{i}$ - span, m;

E - elasticity modulus, $\mathrm{Pa}$;

$\mathrm{J}$ - inertia moment, $\mathrm{m} 4$.

Steel's elasticity modulus E $=206 \cdot 109 \mathrm{~Pa}$.

The cross-section of the strip has the following geometric characteristics: $h=0.003 \mathrm{~m}$, $b=0.2$,

$$
J=\frac{b \cdot h^{3}}{12}=\frac{0.2 \cdot 0.003^{3}}{12}=4.5 \cdot 10^{-10} \mathrm{~m}^{4}
$$

$\mathrm{h}$ - thickness (height) of the strip, m; B-strip width, $\mathrm{m}$

Using Formula III we will find the deflection values for strips: 


$$
\begin{aligned}
& f_{4}=\frac{P_{4} l^{3}}{E J} \cdot \frac{1}{384}=\frac{490 \cdot 0.7^{3}}{206 \cdot 10^{9} \cdot 4.5 \cdot 10^{-10}} \cdot \frac{1}{384}=4.721 \mathrm{~mm}, \\
& f_{2}=\frac{P_{2} l^{3}}{E J} \cdot \frac{1}{384}=\frac{210 \cdot 0.7^{3}}{206 \cdot 10^{9} \cdot 4.5 \cdot 10^{-10}} \cdot \frac{1}{384}=2.023 \mathrm{~mm}, \\
& f_{3}=\frac{P_{3} l^{3}}{E J} \cdot \frac{1}{384}=\frac{350 \cdot 0.7^{3}}{206 \cdot 10^{9} \cdot 4.5 \cdot 10^{-10}} \cdot \frac{1}{384}=3.372 \mathrm{~mm}, \\
& f_{4}=\frac{P_{4} l^{3}}{E J} \cdot \frac{1}{384}=\frac{490 \cdot 0.7^{3}}{206 \cdot 10^{9} \cdot 4.5 \cdot 10^{-10}} \cdot \frac{1}{384}=4.721 \mathrm{~mm} .
\end{aligned}
$$

We will construct dependence (IV) from the results of the calculation (f $\mathrm{H}$ ):

$$
\frac{\Delta f}{l} \leq \frac{1}{400}, \Delta f \leq \frac{1}{400}=\frac{0.7}{400} \leq 0.0017 \mathrm{~m}=1,7 \mathrm{~mm} \prec 2,5 \mathrm{~mm} \text {. }
$$

The calculation results as well as the experiment's results are summarized in Table 1. Proceeding from the results of our calculations, for the purposes of further experimental study let us take a heat-efficiency envelope design characterized as follows: a 800x800x370mm permanent formwork, wall thickness of $32 \mathrm{~mm}$ filled with coarse-pore expanded clay concrete, $\gamma=500 \mathrm{~kg} / \mathrm{m} 3$ bulk density, R6 strength $=0.5 \mathrm{MPa}$, coarse-pore

\begin{tabular}{|c|c|c|c|c|c|c|}
\hline \multirow{2}{*}{$\begin{array}{l}\text { Test } \\
\text { No }\end{array}$} & \multirow{2}{*}{$\begin{array}{l}\text { Strip } \\
\text { No }\end{array}$} & \multicolumn{3}{|c|}{ Deflection value, $\mathrm{mm}$} & \multirow{2}{*}{$\begin{array}{l}\text { Deflection } \\
\text { value, } \\
\text { theoretical, } \\
\mathrm{mm}\end{array}$} & \multirow[t]{2}{*}{ Deviation, $\%$} \\
\hline & & reference & reference & deflection & & \\
\hline \multirow[t]{4}{*}{1} & 1 & 0.00 & 0.60 & 0.80 & 0.76 & 5 \\
\hline & 2 & 0.00 & 2.13 & 2.13 & 2.02 & 6 \\
\hline & 3 & 0.00 & 3.94 & 3.94 & 3.72 & 6 \\
\hline & 4 & 0.00 & 5.03 & 5.03 & 4.72 & 7 \\
\hline \multirow[t]{4}{*}{2} & 1 & 1.00 & 1.82 & 0.82 & 0.76 & 8 \\
\hline & 2 & 1.00 & 3.16 & 2.16 & 2.02 & 7 \\
\hline & 3 & 1.00 & 4.99 & 3.99 & 3.72 & 7 \\
\hline & 4 & 1.00 & 5.98 & 4.98 & 4.72 & 6 \\
\hline \multirow[t]{4}{*}{3} & 1 & 2.00 & 2.81 & 0.81 & 0.76 & 7 \\
\hline & 2 & 2.00 & 4.15 & 2.15 & 2.02 & 6 \\
\hline & 3 & 2.00 & 6.10 & 4.10 & 3.72 & 10 \\
\hline & 4 & 2.00 & 7.03 & 5.03 & 4.72 & 7 \\
\hline \multirow[t]{4}{*}{4} & 1 & 0.00 & 0.79 & 0.79 & 0.76 & 4 \\
\hline & 2 & 0.00 & 2.17 & 2.17 & 2.02 & 7 \\
\hline & 3 & 0.00 & 3.96 & 3.96 & 3.72 & 6 \\
\hline & 4 & 0.00 & 5.09 & 5.09 & 4.72 & 8 \\
\hline \multirow[t]{4}{*}{5} & 1 & 1.00 & 1.83 & 0.83 & 0.76 & 9 \\
\hline & 2 & 1.00 & 3.18 & 2.18 & 2.02 & 8 \\
\hline & 3 & 1.00 & 5.05 & 4.05 & 3.72 & 9 \\
\hline & 4 & 1.00 & 6.15 & 5.15 & 4.72 & 9 \\
\hline 6 & 1 & 1.00 & 1.85 & 0.87 & 0.80 & 9 \\
\hline
\end{tabular}
expanded clay concrete with gravel fraction of $20-40 \mathrm{~mm}, \gamma$ bulk $=400 \mathrm{~kg} / \mathrm{m} 3$ and incylinder crushing strength $\sigma 3=1,2 \mathrm{Mpa}$ - Portland cement 400 and C-3 water reducing agent $(0.2 \%$ of cement mass).

Table 1. The experiment's results 


\begin{tabular}{|l|l|l|l|l|l|l|}
\hline \multirow{7}{*}{} & 2 & 1.00 & 3.24 & 2.18 & 2.10 & 8 \\
\cline { 2 - 7 } & 3 & 1.00 & 5.09 & 4.10 & 3.74 & 9 \\
\cline { 2 - 7 } & 4 & 1.00 & 6.17 & 5.22 & 4.80 & 9 \\
\hline \multirow{7}{*}{7} & 1 & 1.00 & 1.93 & 0.90 & 0.80 & 9 \\
\cline { 2 - 7 } & 2 & 1.00 & 3.30 & 2.20 & 2.12 & 8 \\
\cline { 2 - 7 } & 3 & 1.00 & 5.12 & 4.20 & 3.60 & 9 \\
\cline { 2 - 7 } & 4 & 1.00 & 6.19 & 5.21 & 4.90 & 9 \\
\hline
\end{tabular}

At the next step we make calculations for the CBPB boards according to the diagram in Figure 3.

a) Formwork beam loading diagram

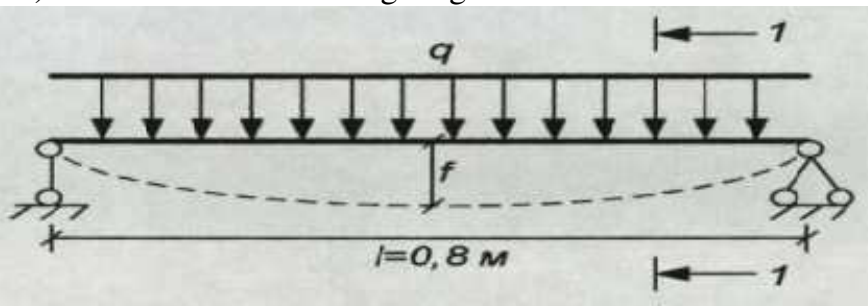

b) Side beam's cross-section

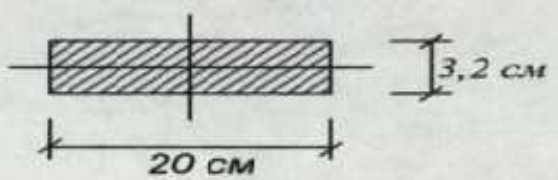

Fig. 3. a) Formwork beam loading diagram, b) Side beam's cross-section

Using this algorithm the lateral pressure exerted by coarse-pore expanded clay concrete will be calculated under the same loading conditions on the formwork beam.

Initial loads: $q=70,210,350,490 \mathrm{~N} / \mathrm{m} ; \mathrm{f}=5 \mathrm{q} 14 / 384 \mathrm{Elx}, \mathrm{E}=3 \mathrm{hPa}$

Next, we will define the deflections, the CBPB material with the $\mathrm{E}=3,000-3,500 \mathrm{mPa}$ modulus and construct the graph (f $\mathrm{H})$ as shown in Fig. 4.

$f \max =1,6 \mathrm{~mm}<\mathrm{fn}=2,5 \mathrm{~mm}$.

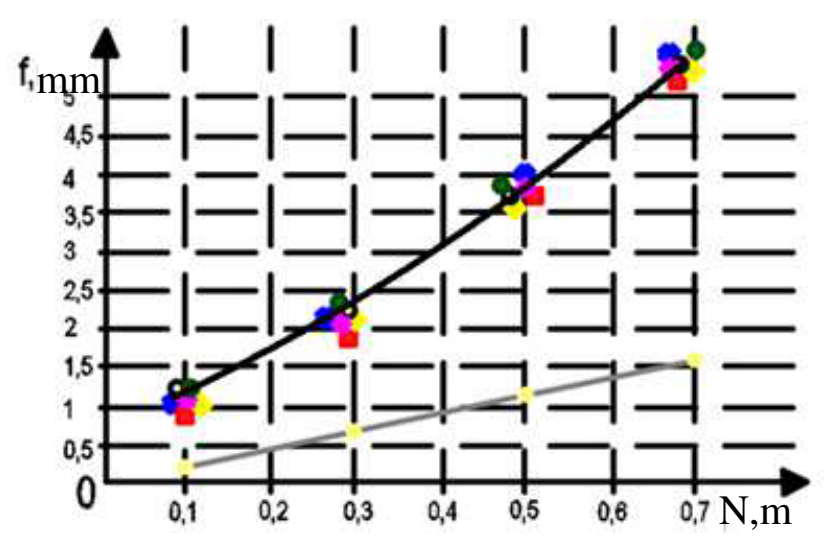

Fig. 4. Design and experimentally derived values of f-H dependencies 
Thus, the formwork's geometrical parameters are $800 \times 800 \times 370 \mathrm{~mm}$ and it can be loaded up to its full height at the time of casting coarse-pore expanded clay concrete; however, for technical reasons and taking into account the need to create an optimum structure while casting as well as the effect of external impulse compaction on the formwork, the layer to be cast should not exceed $400 \mathrm{~mm}$.

With experimental deflection values not exceeding the values obtained by calculation by an average of $6 \%$, the following conclusion can be made: operational effects of coarsepore expanded clay concrete are similar to those of heavyweight concrete and, therefore, it would be correct to assume that the accepted method for calculating lateral pressure has been chosen correctly.

Further calculations and studies have shown that the span of the formwork board can be doubled without compromising its design characteristics, but the increased dimensions and weight of the formwork itself (up to $130 \mathrm{~kg}$ ) would make it difficult to manually assemble and transport. Since a maximum use of manual labor is one of the conditions for undertaking low-rise individual construction projects, we used a $800 \times 800 \times 370 \mathrm{~mm}$ formwork to develop further technological solutions. It stands to reason that the use of mechanized tools will allow for a 1,600x800x370mm formwork to be constructed with relative ease.

\section{Conclusions}

The experimental part of our study has resulted in the following conclusions:

1. Experimental findings on determining the lateral pressure of the mixture on the walls of the formwork (operational effects) have confirmed that the effects of coarse pore expanded clay concrete are similar to those of heavyweight concrete with the nature of the effects demonstrated on a hydrostatic pressure curve.

2. The geometric parameters of the suggested heat-efficient building envelope have been substantiated: a $800 \times 800 \times 370 \mathrm{~mm}$ block of CBPB filled with coarse-pore expanded clay concrete $\gamma=500 \mathrm{~kg} / \mathrm{m} 3$.

\section{References}

1. Anpilov S. M.: Shuttering systems for monolithic construction Anpilov S. of AVS M / publishing house - M.: Educational edition. (2005)

2. A.A. Afanasyev, Construction of buildings and constructions from monolithic reinforced concrete / A.A. Afanasyev - Stroyizdat - M (2012)

3. M.Z. Weinstein, Deformativnye of property of light concrete on porous fillers at compression / M. Z. Weinstein//Works NIISM - Alma-Ata. - Collection 5(7)-(2008)

4. V.N. Vernigorova, Modern methods of studying the properties of building materials. Vernigorova, P.I. Makridin, Yu.A. Sokolova // Publishing house ABC - M., (2003)

5. E.M. Pugach, Technology of production of three-layer blocks for the construction of energy-efficient enclosing structures // Thesis for the competition uch. Degrees Ph.D. - M.: - MSSU (2005)

6. SNiP 2.01.02-85 *. Fire regulations / / Stroyizdat - M., (1995)

7. A.A. Afanasyev, Technology of construction processes / A.Afanasyev, N.N. Danilov, V.D. Kopylov // Proc. - Higher School - M., (2006)

8. N.I. Makridin, Structure, Deformability, Strength and Criteria for the Destruction of Cement Composites / N.I. Makridin, I.N. Maksimova / / Ed. Saratov University - (2005)

9. Modern walls and facades. Overview of technical capabilities and materials // Know-how $2-(2010)$ 
10. Typical technological map for concrete and reinforced concrete works $31032 \mathrm{~K}$. Concreting of typical floors in the block-panel formwork // SNIIMTOP-M., (2005) 